\title{
Bending Test and Simulation of Welded Galvanized Steel Pipes
}

\author{
Mohammed SABER
}

\begin{abstract}
Galvanized pipes have to be either welded together or to other components. In this paper, experimental and finite element (FE) studies were carried out to investigate the behaviour of welded A53 B galvanized pipes subjected to bending loading. Firstly, tensile tests of the pipe material and of the weld metal were carried out. Pieces of the galvanized pipe, each of $300 \mathrm{~mm}$, were welded together using arc welding. A welded pair of pipes was sliced longitudinally and subjected to bending load in two different directions: root-bending and face-bending. FE study was carried out on models of the welded pipes. The obtained results revealed that the pipe material showed non-homogeneity in tensile testing. Moreover, the face-bending strength was two times the root-bending strength. The FE analysis was accurately able to predict the maximum loading the joint can support.
\end{abstract}

Keywords: face-bending test; finite element analysis; galvanized pipes; root-bending test; weld metal

\section{INTRODUCTION}

Galvanized steel pipes are widely used in industry and in constructional works [1]. Typical application of these pipes is in fluid transfer, power plants piping, high pressure and low-pressure boiler tubes, petroleum cracking, scaffolding, etc. Because of their corrosive resistance, galvanized pipes are ideal to be used in chemical plants and harassment environment. These pipes are available in market in diameters ranges from $10 \mathrm{~mm}$ to $900 \mathrm{~mm}$ and wall thickness ranges from $1,5 \mathrm{~mm}$ to $50 \mathrm{~mm}$. In the current study, hot-dipped galvanized steel pipes made of A53 B steel grade were considered. A 53 B galvanized steel pipe areis intended for mechanical and pressure applications. It is also suitable for uses in steam, water, gas and airlines. It has good weldability and formability.

Extensive research was carried out on the corrosion of the galvanized steel, e.g. [2-4]. However, little research was found to consider the mechanical behaviour of galvanized steel pipes. Rafiqul et al [5] studied the effects of the heat input on the mechanical properties of the welded galvanized steel pipes. They concluded that the metal inert gas (MIG) is suitable for welding galvanized steel pipes.

Although standards have been set to ensure the mechanical properties of galvanized pipes and structural sections, thermal cracking during galvanizing process may occur [6] and [7]. This thermal cracking is a life limiting parameter of the pipes. In many applications, galvanized steel pipes are welded together to have longer pipes. Moreover, these welded pipes could be subjected to tensile, compression, bending or torsional loading. Galvanized pipes used in [1] are subjected to bending due to buckling load. It was found that for the ratio of $L / d$ more than six ( $L$ is the pipe's length and $d$ its diameter) buckling took place. The bending stress developed in structural components is the most sever type of stresses. It could lead to early failure of components, specifically, if it is in a completely reversed nature [8].

In this paper, three $300 \mathrm{~mm}$ length pieces of an A53 B galvanized pipe were cut. Two pieces were welded together and then subjected to bending loading in two different directions: root-bending and face-bending. A set of sub-size tensile specimens were then cut of a third pipe piece. Those specimens were used to measure the mechanical properties of the pipe material. In addition, a block of weld metal was manufactured and tensile specimens were, then, cut out of that block and tested to measure the mechanical properties of the weld metal. The mechanical properties of the pipe material and the weld metal were then fed into the finite elements (FE) commercial package ABAQUS to predict the bending behaviour of the welded pipe. The obtained results also showed that the strength of the face-bending was two times that of the root-bending. The FE analyses succeeded to predict the loading capacity of the welded pipes accurately.

\section{MATERIALS}

The tested galvanized pipe was made of A53 B steel. The chemical composition of the pipe material is given in Tab. 1. The pipe was coated with zinc inside and outside by the hot-dip process. The pipe had an outer diameter of $42,2 \mathrm{~mm}$ and wall thickness of $3 \mathrm{~mm}$. Three pieces were cut off a four-meter pipe. Each piece was $300 \mathrm{~mm}$ in length. In addition to the pipe material, the weld metal was considered as well. A commercial metal shielded arc welding electrode, designated AWS E 6013, was used. This type of electrode was used for its availability in the local industrial community and for its high strength.

Table 1 Chemical Composition of A53 B grade steel galvanized pipes [9]

\begin{tabular}{|c|c|c|c|c|c|c|c|c|c|}
\hline $\mathrm{C}$ & $\mathrm{Mn}$ & $\mathrm{P}$ & $\mathrm{S}$ & $\mathrm{Cu}$ & $\mathrm{Ni}$ & $\mathrm{Cr}$ & $\mathrm{Mo}$ & $\mathrm{V}$ & $\mathrm{Fe}$ \\
\hline 0,30 & 1,2 & 0,05 & 0,045 & 0,40 & 0,40 & 0,40 & 0,15 & 0,08 & balance \\
\hline
\end{tabular}

\section{EXPERIMENTAL WORK}

Three-point bending tests were carried out on welded galvanized pipe. Firstly, the edges of the pipe were chamfered to depth of $1,5 \mathrm{~mm}$ and an angle of $45^{\circ}$. The pipe pieces were then welded together by an electric arc welding process using a high strength-welding electrode designated as AWS E 6013. The extra welding material (i.e. the reinforcement) was removed. The welded pipe pieces were, then, cut longitudinally into four slices. Those slices were used in the three-point bending testing program. A set of tensile testing specimens were, also, cut out of another pipe piece. The strength of the weld metal was measured using tensile specimens made of the weld 
metal electrode. Details of the experimental testing procedure are given in the following sections.

\subsection{Tensile Testing}

In order to measure the strength of the pipe material, a set of three sub-size tensile testing specimens were tested. The specimens were cut longitudinally of a pipe piece. Sub-size tensile specimens were chosen to account for the pipe curvature. Geometry, dimensions and orientation of the tensile specimens are shown in Fig. 1.

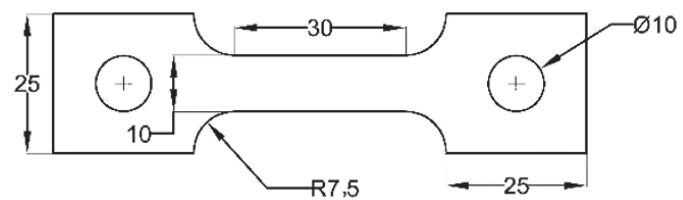

Dimensions in $\mathrm{mm}$

(a)

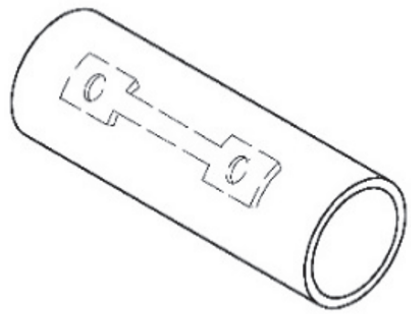

(b)

Figure 1 Sampling the tensile specimens of the tube: (a) and the specimen's geometry and dimensions and (b) specimen orientation.

Structural integrity of welded structures depends largely on the mechanical properties of the weld metal. In order to measure the strength of the weld metal, used in the current study, a bock of weld metal was manufactured by a series welding beads deposited one above another, see Fig. 2a. Careful cleaning of the weld surface after each bead was done. The used welding electrode was designated as AWS E 6013. Standard tensile testing specimens were cut out of the weld metal block in the welding direction, see Fig. 2. Those specimens were then tested on a universal testing machine.

All the tensile testing of the pipe material and on the weld metal was carried out on a universal testing machine TM-300 with dual-column, stand-alone system with 300 $\mathrm{kN}$ maximum loading capacity.

\subsection{Pipe Bending Testing}

The welded pipes were subjected to bending tests. The pipes were cut longitudinally to four equal segments, as shown in Fig. 3. This is to ease the testing procedure and to characterize the difference between bending through the face and bending through the root. Fig. 4 illustrates the experimental setup for the three-point bending tests. Geometry and dimensions of the pipe specimens along with the bending test layout are shown in Fig. 5. The facebending test was performed such that the weld face was on the outside of the bend radius. The root-bending test was performed such that the weld root was on the outside of the bend radius.

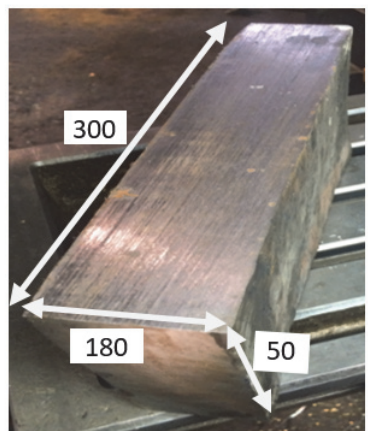

(a)

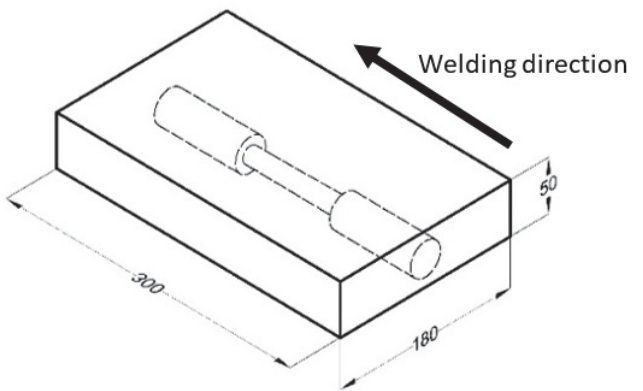

(b)

Figure 2 Sampling the tensile specimen of the weld metal. (a) In-house made block of weld metal. (b) Sampling the specimen out of the weld metal block. (Dimensions in $\mathrm{mm}$ )
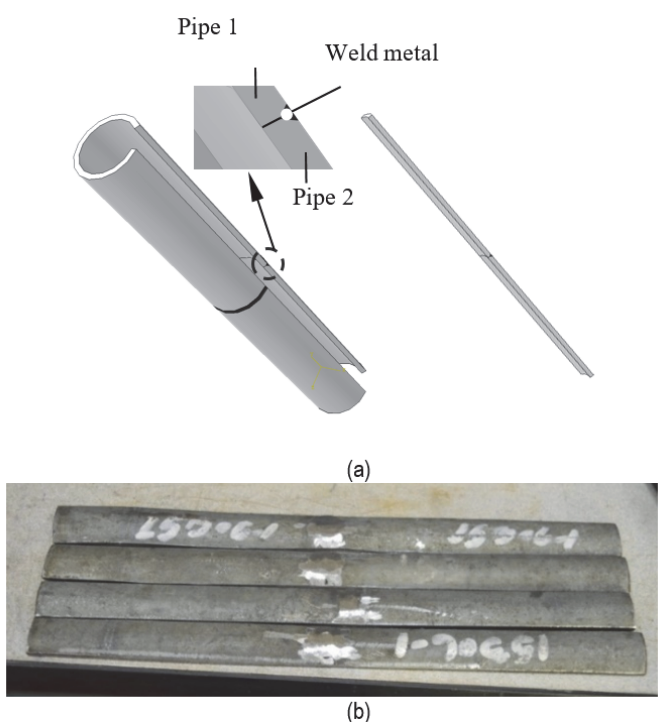

Figure 3 Sampling of bending specimen of the welded pipes

\section{FINITE ELEMENT MODELLING}

A 3D finite element model of welded pipes was created using the FE commercial package Abaqus [10]. The model consisted of 16048 linear hexahedral elements of type C3D8R. Fine mesh was used in the weld zone while coarse mesh was used elsewhere. The loading pin and the two supports were modelled as rigid shell. Geometry and dimensions of the model were the same as those used in the experimental work. Fig. 6a shows the FE model and the details of the welded zone are shown in Fig. 6b. Due to symmetry of the FE model, only one-half of the model was considered. Material properties of the pipe material and the weld metal which were used in the FE analysis are given in Tab. 2. 


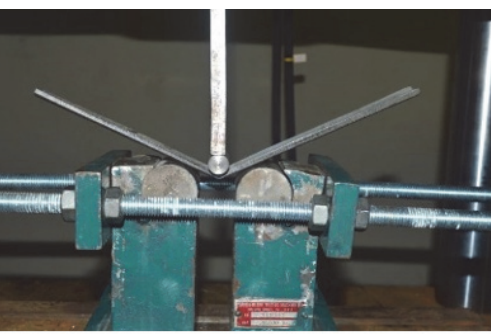

Face-bending

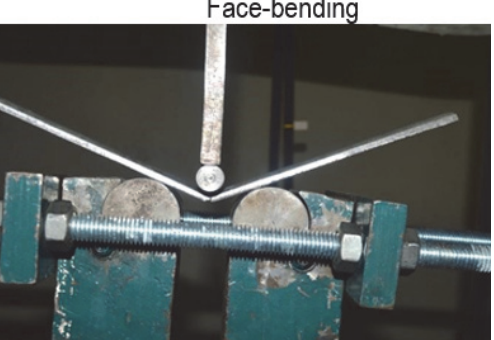

Figure 4 Experimental set-up for the three-point bending test

In order to account for potential damage in the weld metal, ductile damage model was used in the FE analyses. Since the stress concentration was expected to occur in the weld metal, damage model was used for the weld metal. However, the pipe material was assumed to be elasticperfect-plastic material. Plastic true stress-true strain date was extracted from the stress-strain curve for the weld metal, given in Fig. 10, and implemented in the FE analyses.

Table 2 Mechanical properties used in the FE analysis.

\begin{tabular}{|l|c|c|}
\hline & Pipe material & Weld metal \\
\hline Density / kg/m & 7800 & 7800 \\
\hline Tensile strength / MPa & 416 & 923 \\
\hline Yield Strength / MPa & 400 & 750 \\
\hline Modulus of Elasticity / GPa & 210 & 214 \\
\hline Poisson's ratio / $v$ & 0,3 & 0,3 \\
\hline
\end{tabular}

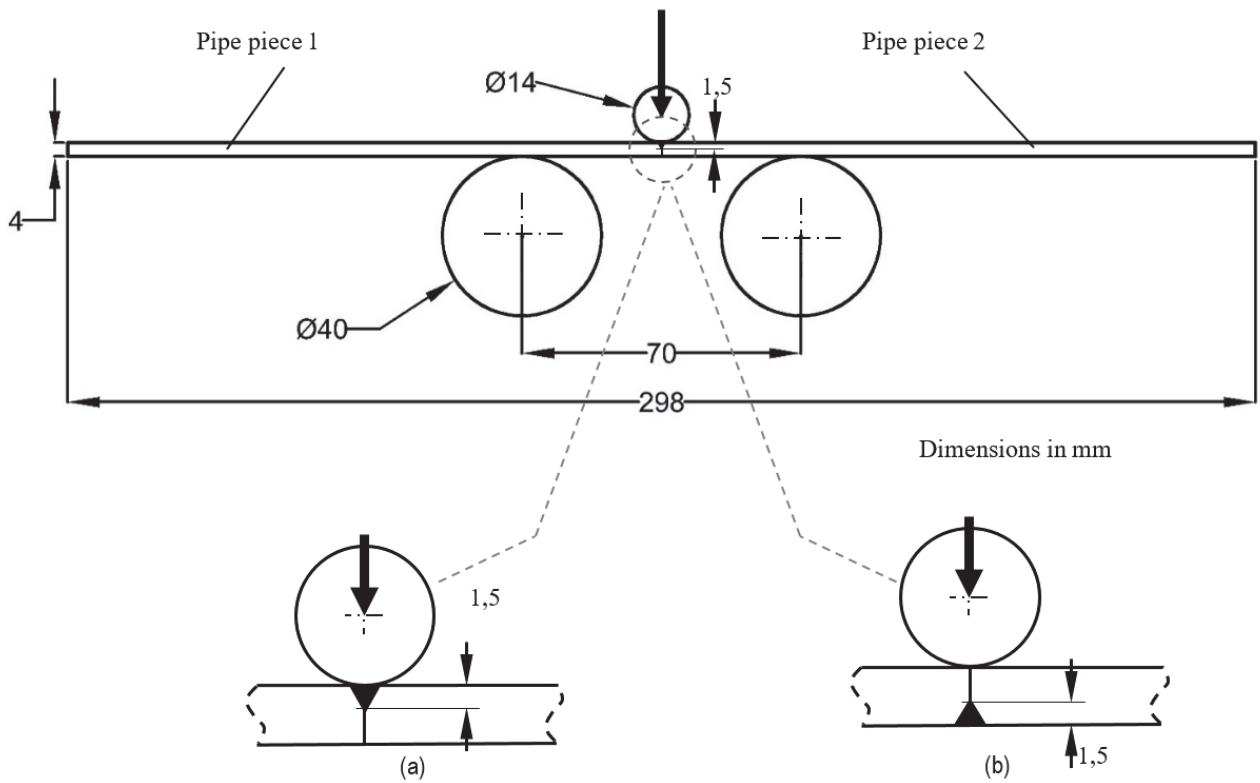

Figure 5 Arrangement for the three-point bending test (a) for root-bending and (b) for face-bending.
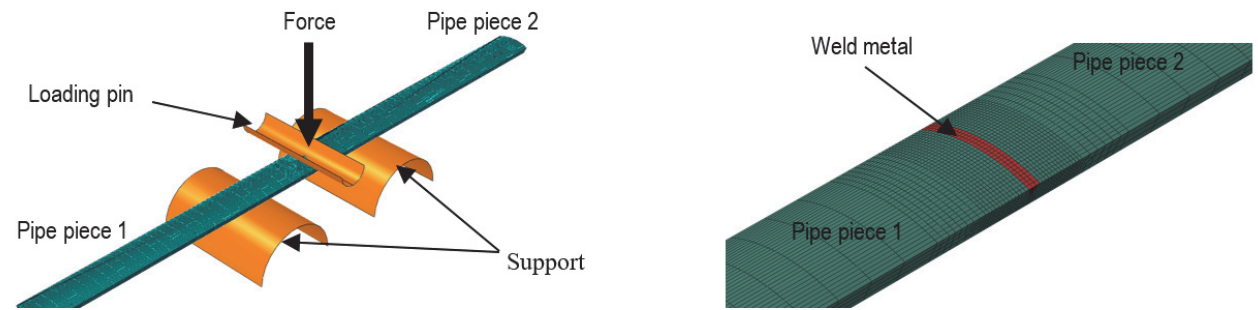

Figure 6 The FE model of the welded pipe.

In the adopted ductile damage model, the equivalent plastic at the onset of damage, $\bar{\varepsilon}_{o}^{p l}$, is considered as a function of the uniaxial plastic strain at necking, $\varepsilon_{n}^{p l}$, and stress triaxiality $\alpha$ according to the following equation [11]:

$\bar{\varepsilon}_{o}^{p l}(\alpha)=\varepsilon_{n}^{p l} \cdot \exp [-0,5 \cdot(\alpha-1 / 3)]$
The incremental increase of the damage parameter, $\Delta D$, is calculated at the end of each increment of the analysis. Once the value of the damage parameter $D$ reaches one in an element, the element is considered failed and no longer supports any loading. Damage incremental, $\Delta D$, and damage parameter $D$ are calculated as follows [10]:

where $\alpha$ is the stress triaxiality, which equals $1 / 3$ for the uniaxial tensile testing. 


$$
\begin{gathered}
\Delta D=\frac{\bar{\varepsilon}^{p l}}{\bar{\varepsilon}_{o}^{p l}} \geq 0 \\
D=\int \frac{\bar{\varepsilon}^{p l}}{\bar{\varepsilon}_{o}^{p l}}=1
\end{gathered}
$$

where $\bar{\varepsilon}^{p l}$ is the equivalent plastic strain.

\section{$5 \quad$ RESULTS AND DISCUSSION}

Fig. 7 shows the failed tensile testing specimens of the pipe material. It can be seen that all of the specimens failed within the gauge length. The stress-strain curves for the shown specimens are given in Fig. 8. The figure shows that the tube materials show identical behaviour of low carbon steel. The $0,2 \%$ proof strengths of test \#1, test \#2 and test \#3 are $400 \mathrm{MPa}, 279 \mathrm{MPa}$ and $312 \mathrm{MPa}$, respectively. The ultimate tensile strength $\left(S_{\mathrm{u}}\right)$ of the three tests is $416 \mathrm{MPa}$, $305 \mathrm{MPa}$ and $333 \mathrm{MPa}$, respectively. Clearly, it can be seen that the yield strength obtained from all of the specimens is more that $90 \%$ of the corresponding ultimate tensile strength. The specimens' ductility is comparable. It is worth noting that the width of the gauge length was chosen to get a flat gauge section as possible as it can be. Ma et al in [12] found that the proof strength of curved specimen is about $18 \%$ higher than that obtained from flat specimens. Moreover, the pipe material showed anisotropic behaviour as its mechanical properties, i.e. $S_{\mathrm{u}}$ and $S_{\mathrm{y}}$ were different around the pipe circumference. This can be attributed to the pipe manufacturing process.

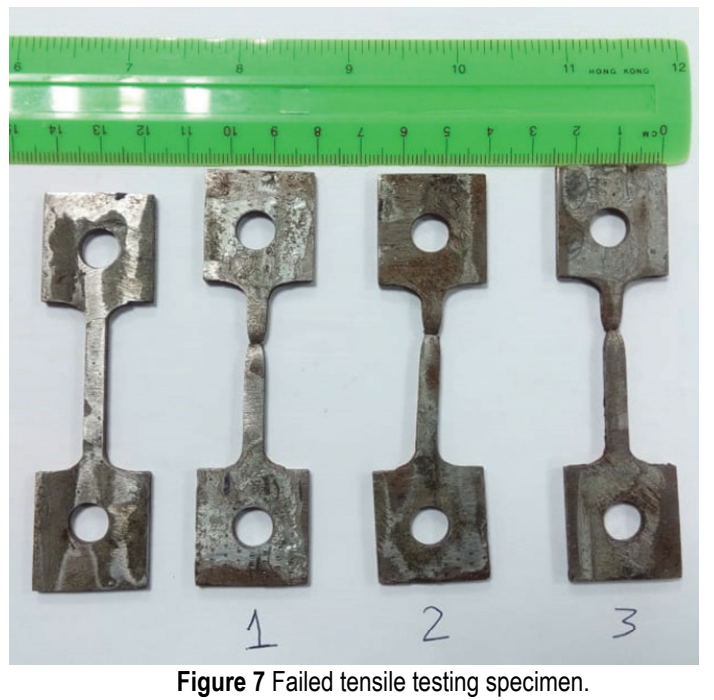

The weld metal was also assessed by conducting tensile testing of specimen cut of a block of weld metal. Fig. 9 shows the failed specimen of the weld metal. The necking and, hence, the failure position of the specimen are close to the grip of the testing machine. This odd behaviour of testing the weld metal is expected as the specimen was cut from a block of the weld metal where non-homogeneity exists. This non-homogeneity is inherited in welding processes. Fig. 9c shows little shear lib of the cross-section with high tearing area. This failure mode characterizes the high strength and high hardness of the weld metal. The ultimate tensile strength of the weld metal was found to be $923 \mathrm{MPa}$ with the yield strength $\left(S_{\mathrm{y}}\right)$ of around $750 \mathrm{MPa}$. These values are higher than those recorded for the electrode material $\left(S_{\mathrm{u}}=530\right.$ and $S_{\mathrm{y}}=500 \mathrm{MPa}$, [13]). This difference can be attributed to the cyclic thermal loading of the weld metal during the welding process. Clearly, the higher strength of the weld metal can add to the strength of the joint; however, it may reduce the joint fracture toughness.

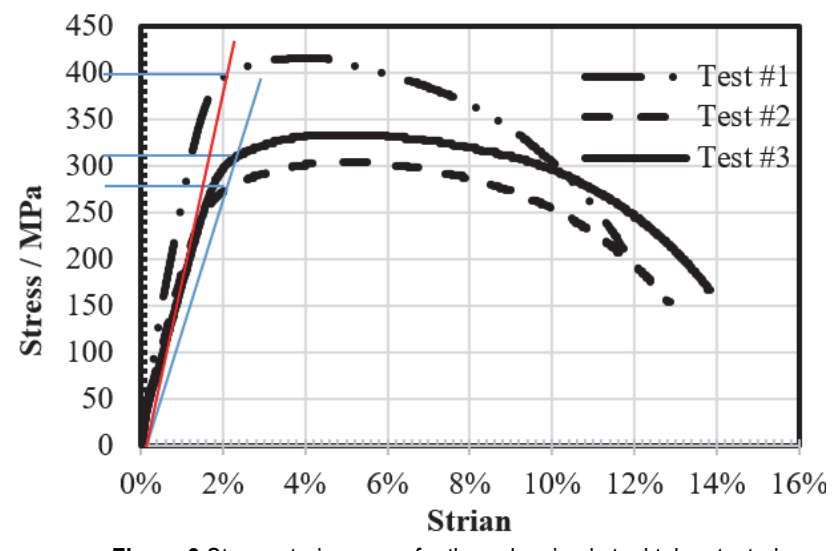

Figure 8 Stress-strain curves for the galvanized steel tubes tested.

Fig. 10 illustrates the load-displacement curve for rootbending tests. The results obtained from the two tests are identical. Clearly, it can be seen that the weldment shows elastic behaviour followed by sharp decrease in its load carrying capacity. The maximum attained load for the rootbending is $850 \mathrm{~N}$. On the other hand, the load-displacement curves for face-bending tests are shown in Fig. 11. It can be seen that the strength of the face-bending is two times that of the root-bending. The maximum attained load for the face-bending is about $1500 \mathrm{~N}$. In addition, the displacement at failure for the face-bending is around 1,5 that of root-bending test. The large area under the facebending curve is an indication of the higher toughness of the face-bending specimens when compared to that of the root-bending specimens. Lower toughness of the rootbending specimen can be attributed to the sharp notch in the specimen side opposite the loading pin. This causes high stress concentration at that notch and, hence, accelerates the failure of the specimens.

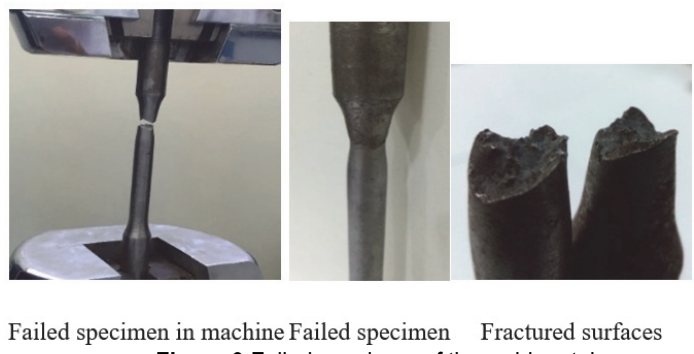
Figure 9 Failed specimen of the weld metal.

Fig. 12 illustrates the results of the FE analysis for the root-bending modelling. Clearly, and as expected, stresses are concentrated at the weld zone where the bending moment is maximum. A comparison between the deformed and un-deformed shapes of the root-bending models is given in Fig. 13. Damage evolution for the face-bending models is shown in Fig. 14. Once the damage parameter in 
an element reaches the value of one, this element no longer supports any load and, hence, stresses are reduced to zero. The FE obtained results showed once the damage started, the total collapse of the joints took place in very short time.

The maximum load supported by the root-bending testing was $800 \mathrm{~N}$. The FE results for the root-bending modelling showed the maximum load attained by the model was $775 \mathrm{~N}$, which agrees very well with experimental results. For the face-bending, the maximum attained load by experiment and by FE modelling was found to be $1475 \mathrm{~N}$ and 1284, respectively. Generally, it can be seen that both the experimental testing and the FE results match very well for both the two bending arrangements.

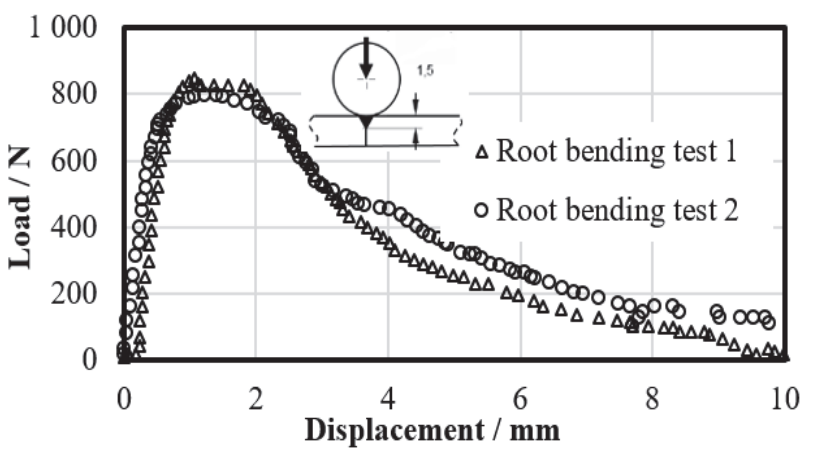

Figure 10 Load against displacement for root-bending tests.

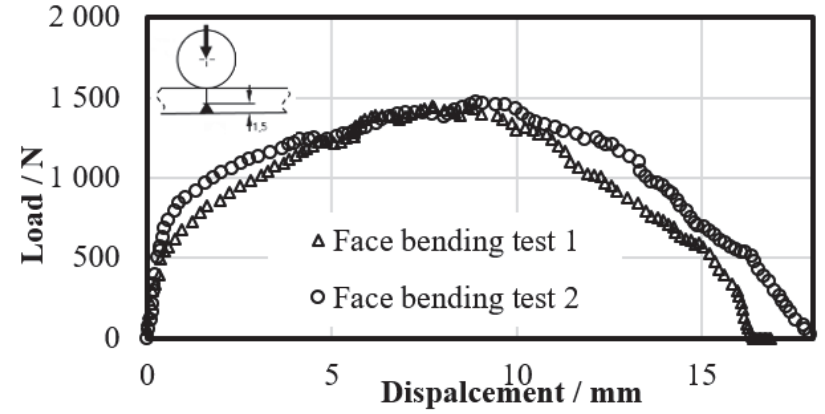

Figure 11 Load against displacement for face-bending tests.

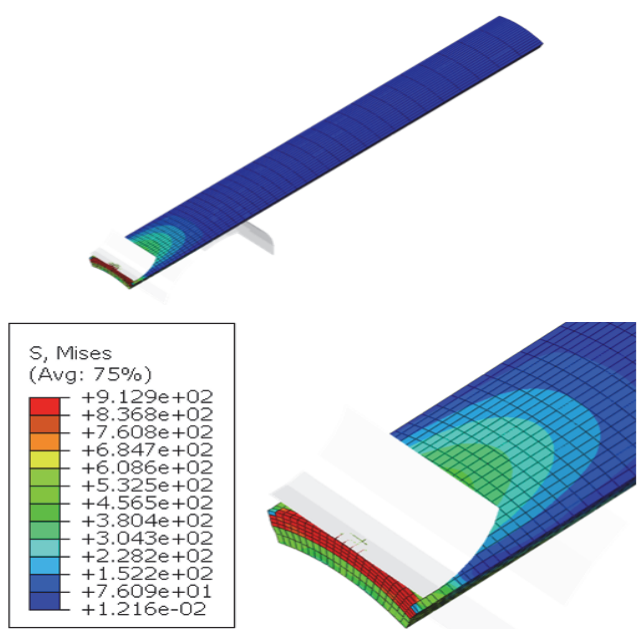

Figure 12 Stresses are concentrated in the weld metal.

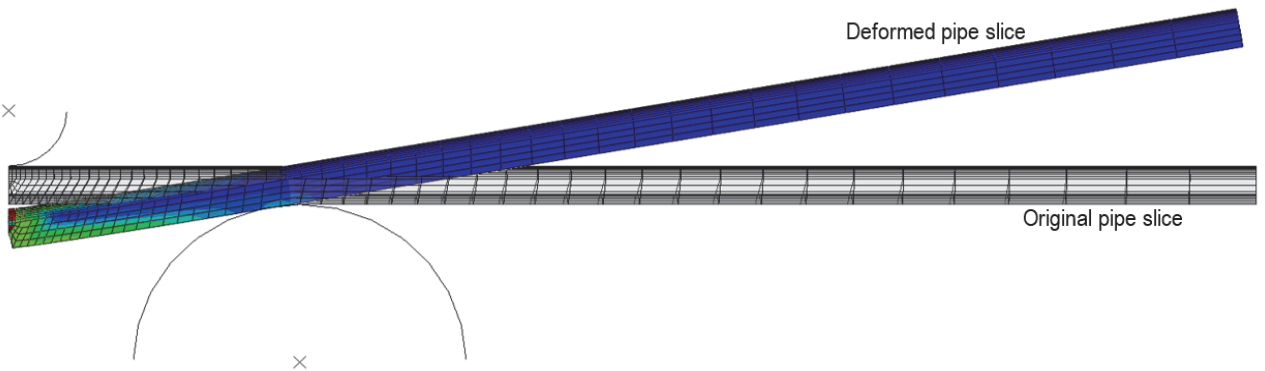

Figure 13 Deformed pipe slice, i.e. after bending, compared to its original shape, i.e. before bending.
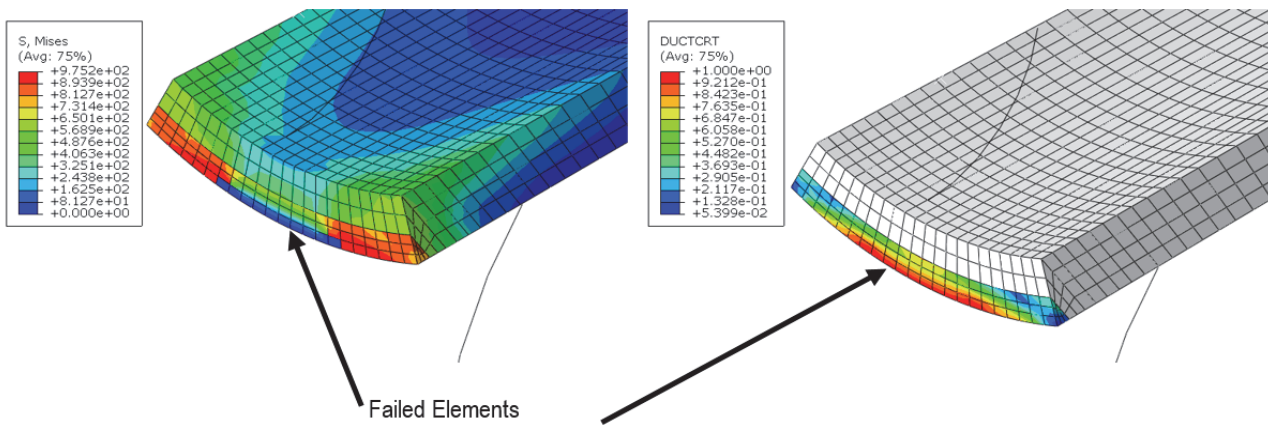

Figure 14 Damaged elements no longer support any load.

\section{CONCLUSIONS}

Experimental study of the behaviour of A53 B welded galvanized steel pipes was carried out. The mechanical properties for the pipe material and for the weld metal were determined. Two welded pipes were sliced and then subjected to bending test in face-bending and root-bending arrangements. FE analyses were carried out to show the stress distribution and to predict the failure loading of specimens.

It can be concluded that the pipe material showed slight non-isotropic behaviour. However, all the obtained values of the tensile strength of the different specimens fell within the reference values provided by the pipes manufacturers. In addition, the weld material showed high strength when compared to the pipe material. The obtained 
results showed that although the welded metal is two times stronger than the pipe material, the failure of the welded pipe started and continued in the weld metal. This can be attributed to the high stress concentration at the welding zone as predicted by the FE analysis. The obtained results also showed that the strength of the face-bending was two times that of the root-bending. The FE analyses succeeded to predict the loading capacity of the welded pipes accurately.

\section{Acknowledgement}

The author acknowledges the Deanship of Scientific Research at King Faisal University for the financial support under Nasher Track (Grant No. 186352).

\section{REFERENCES}

[1] Alhussiny, F., Sheikh, M. N., \& Hadi, M. N. S. (2017). Behaviour of Small Diameter Steel Tubes Under Axial Compression. $\quad$ Structures, 11, 155-163. https://doi.org/10.1016/j.istruc.2017.05.006

[2] ASTM (2018). Standard Specification for Structures. I (Reapproved), 1-5. https://doi.org/10.1520/F3114-15.2

[3] Budynas, R. G. \& Nisbett, J. K. (2015). Shigley's Mechanical Engineering Design (10th ed.). McGraw-Hill Education.

[4] ABAQUS/Standard User's Manual (2015). Version 2016. Providence, RI: DassaultSystèmesSimulia Corp.

[5] Delaunois, F., Tosar, F., \& Vitry, V. (2014). Corrosion behavior and bio-corrosion of galvanized steel water distribution systems. Bio-electrochemistry, 97, 110-119. https://doi.org/10.1016/j.bioelechem.2014.01.003

[6] Della Rovere, C. A., Silva, R., Moretti, C., \& Kuri, S. E. (2013). Corrosion failure analysis of galvanized steel pipes in a water irrigation system. Engineering Failure Analysis, 33, 381-386. https://doi.org/10.1016/j.engfailanal.2013.06.024

[7] Ma, J. L., Chan, T. M., \& Young, B. (2015). Material properties and residual stresses of cold-formed high strength steel hollow sections. Journal of Constructional Steel Research, 109, 152-165. https://doi.org/10.1016/j.jcsr.2015.02.006

[8] Masubuchi, K. (1980). Analysis of Welded Structures: Residual Stresses, Distortion, and their Consequences (D. W. Hopkins (ed.)). Pergamon Textbook.

[9] Minnoş, B., Ilhan-Sungur, E., Çotuk, A., Güngör, N. D., \& Cansever, N. (2013). The corrosion behaviour of galvanized steel in cooling tower water containing a biocide and a corrosion inhibitor. Biofouling, 29(3), 223-235. https://doi.org/10.1080/08927014.2012.763117

[10] Pavlović, M., Marković, Z., Veljković, M., Bucrossed, D., \& Signevac, D. (2013). Bolted shear connectors vs. headed studs behaviour in push-out tests. Journal of Constructional Steel Research, 88, 134-149. https://doi.org/10.1016/j.jcsr.2013.05.003

[11] Rafiqul, M. I., Ishak, M., \& Rahman, M. M. (2012). Effects of heat input on mechanical properties of metal inert gas welded $1.6 \mathrm{~mm}$ thick galvanized steel sheet. IOP Conference Series: Materials Science and Engineering, 36, 012011. https://doi.org/10.1088/1757-899X/36/1/012011

[12] Sun, M. \& Ma, Z. (2019). Effects of heat-treatment and hotdip galvanizing on mechanical properties of RHS. Journal of Constructional Steel Research, 153, 603-617. https://doi.org/10.1016/j.jcsr.2018.11.012

[13] See http://www.weldwire.net/weld_products/ww6013/

\section{Contact information:}

Mohammed SABER, Ph.D., Assistant professor (Corresponding author)

1) Department of Mechanical Engineering, College of Engineering, King Faisal University,

P.O. Box 380 Al-Ahsa, 31982, Saudi Arabia

Phone: +966135898436

Email: msaber@kfu.edu.sa

2) Department of Production Engineering and Mechanical Design, Faculty of Engineering, Port Said University,

Port Fouad, Port Said

Egypt 